Article

\title{
Bending Limit Tests for Ultra-Thin Liquid Crystal Polymer Substrate Based on Flexible Microwave Components
}

\author{
Yu Lan 1 and Yuehang $\mathrm{Xu}$ *(1) \\ School of Electronic Science and Engineering (National Exemplary School of Microelectronics), \\ University of Electronic Science and Technology of China, Chengdu 611731, China; Lanyu136482942@163.com \\ * Correspondence: yuehangxu@uestc.edu.cn
}

Received: 19 September 2018; Accepted: 16 October 2018; Published: 20 October 2018

\begin{abstract}
In this paper, bending limit tests for one ultra-thin liquid crystal polymer (LCP) substrate (Rogers 3850) based on the mechanical properties of flexible microwave microstrip components are presented. First, a set of $50 \Omega$ microstrip lines, a band-pass filter, and a stepped impedance filter in X-band, are designed by using double clapped LCPs with $50 \mu \mathrm{m}$ thickness of substrate and $18 \mu \mathrm{m}$ thickness of copper, which is fabricated by conventional photolithography. Then, the limit tests of the flexibility of the LCP microwave microstrip components are presented, and the range of the bending limit radius, from $1 \mathrm{~mm}$ to $0.75 \mathrm{~mm}$, is demonstrated from the testing results. It is found that the cause for component failure is fracture of the copper (18 $\mu \mathrm{m}$ thickness) laminate, according to the bending limit test experiments. Finally, the analysis of the reasons for the collapse of the microwave components, under bending situations, is explored. The results from this work would be useful for further designs of the flexible microwave devices and systems on LCP substrates, with compact sizes and good performance.
\end{abstract}

Keywords: bending limit test; flexible filters; microwave components; LCP substrate; bending effect

\section{Introduction}

As the development of flexible electronic devices and system modules, widely concerned in radio frequency (RF)/microwave/millimeter-wave and biomedical applications, are increasing, flexible materials have been attracting wide attention in high frequency applications. Liquid crystal polymer (LCP) substrate has also been showing its superiorities in some applications of microwave and millimeter-wave circuits, due to its features of excellent loss tangent (approximately 0.005 over the entire $\mathrm{RF}$ range up to $170 \mathrm{GHz}$ [1,2], stable and desirable electrical characteristics for wide band, extremely low moisture absorption, and low thermal expansion coefficient. The ultra-thin substrate and good dimensional stability of LCP make it show much excellent bending and stretching characteristics than other traditional rigid dielectric substrates. Ease of bending also makes this material suitable for reel-to-reel processing and conformal applications, applicable for non-planar surroundings. In the past decade, many millimeter-wave components, emerging structures, and system modules based on LCP substrates have been reported [3-8]. These applications show that LCP substrates could cover the frequency range from $1 \mathrm{GHz}$ to $100 \mathrm{GHz}$, and the circuits on LCP substrates always had the advantages of light weight, low-cost packaging, and easy fabrication.

Recently, some applications of LCPs, regarding bending tests, had been presented, such as a compact broadband flexible antenna utilized in wireless local area network (WLAN) and upper ultra-wideband (UWB) systems fabricated on LCPs at a thickness of $127 \mu \mathrm{m}$ [9]. A bent transmission line and a $20 \mathrm{GHz}$ interdigital coupled lines filter on the LCPs [10] were demonstrated in bending and 
flat situations. Inkjet printing technology was introduced for the fabrication of flexible circuits with the advantages of more convenience, low-cost, and much more stability, a K-band hairpin band-pass filter [11], a $25 \mathrm{GHz}$ narrow-band band-pass filter [12], and a $26 \mathrm{GHz}-33 \mathrm{GHz}$ series-fed two-dipole antenna comprising a balun filter as the feeding port [13], based on an LCP substrate with thickness of $100 \mu \mathrm{m}$ that had been presented using inkjet printing technology. In our previous works [14,15], an interdigital two-stage hairpin band-pass filter, based on LCPs which consist of two half-wavelength $(\lambda / 2)$ microstrip line resonators with intercoupling method, was introduced, with compact size and good performance, and the bending effect research shows that the S-parameters of the filter are not sensitive to bending behavior.

All the above references addressed the outstanding flexibility of LCP substrates, but they did not conduct limit bending tests to characterize a limit tolerance of microwave devices on LCP substrates. The limit bending tolerance would be a very significant parameter for future flexible applications under repeated bending and stretching conditions, such as wearable devices mounted on the skin, collecting the health information from bodies $[16,17]$, and high-speed wireless communication systems integrated in clothes or other folding objects, in the future.

This paper goes further on the development of the bending tests presented in $[14,15]$, and demonstrates further results from bending limit tests for this LCP substrate. Indeed, for getting the bending limit parameters before the circuits collapsed, the breakdown tests were used to extract the bending limit radius. Finally, in order to pave the way for the further design of the flexible circuits, the failure mechanism of these components are researched and presented, giving the further design process some guidelines to avoiding time-consuming and cost-consuming experiments.

This paper is organized as follows: Section 2 presents the design processes and experimental results of $50 \Omega$ microstrip lines, band-pass filters, and low-pass filters. Section 3 presents the bending limit test experiments and discussion of the reasons for the interface failure and sharply deteriorating performance. Finally, the conclusion for this work is presented in Section 4.

\section{Device Design}

Transmission lines are always the critical components for microwave and mm-meter wave circuits, which are mandatorily used for building almost all passive circuits, including matching networks, hybrid couplers, baluns, filters, etc., so high-performance and more compact transmission lines in different technologies have the same aim of reducing the area of the devices and getting a higher integration level. In this application, the LCP substrate 3850 [18] is offered as a double copper-clad laminate with constant relative permittivity of 3.0, stable loss tangent of 0.0025 , substrate thickness of $50 \mu \mathrm{m}$, and copper laminate thickness of $18 \mu \mathrm{m}$. The chemical structure of the LCP substrates are shown in Figure 1a. The width of $50 \Omega$ microstrip line is $120 \mu \mathrm{m}$, as shown in Figure 1c. A $10 \mathrm{GHz}$ stepped impedance low-pass filter consists of six different length microstrip lines with high impedance of $60 \Omega$ (microstrip width $0.08 \mathrm{~mm}$ ) and low impedance of $5 \Omega$ (microstrip width $2 \mathrm{~mm}$ ), as shown in Figure 1b. The high impedance ratio between high impedance microstrip line and low impedance line always offer high performance for low-pass filter, but the width of $0.08 \mathrm{~mm}$ had reached our PCB fabrication limit. A band-pass filter consists of two identical half-wavelength $(\lambda / 2)$ microstrip lines, and two tapped I/O lines at each side of $\lambda / 2$ microstrip lines, as shown in Figure 1d. This kind of symmetric feed structure is commonly used [19] to generate two transmission zeros in the stop-band. The ground coplanar waveguide (GCPW), with a $0.085 \mathrm{~mm}$-wide center strip and a $0.075 \mathrm{~mm}$-wide gap, was employed as the input and output of the RF signals. The reasons of selecting a $50 \Omega$ microstrip lines, stepped impedance low-pass filters, and interdigital band-pass filter as the geometry of bending test, is that the microstrip lines and filters are the foundation of microwave PCB circuits. Meanwhile, we can also study how the bending behavior affects the coupling effects of the microwave circuits, by comparing the stepped impedance and interdigital filters. 


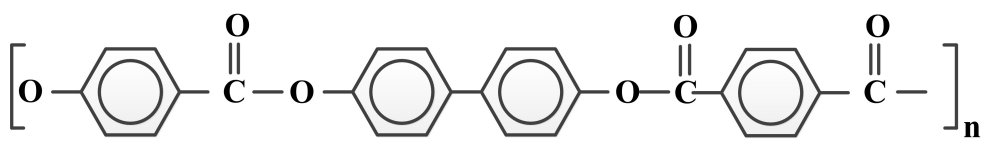

(a)

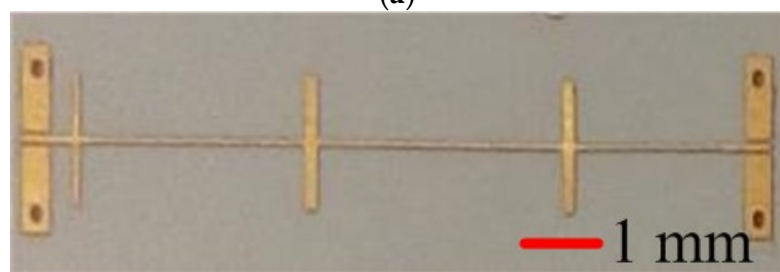

(b)

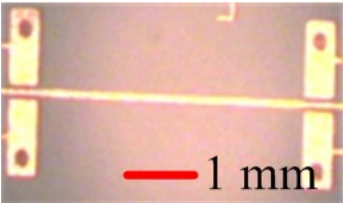

(c)

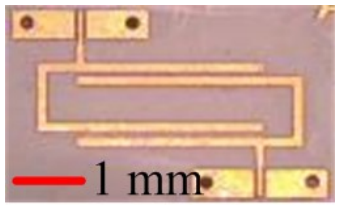

(d)

Figure 1. (a) Chemical structures of liquid crystalline polymer, (b) photograph of the 10GHz stepped impedance low-pass filter, (c) image of the $50 \Omega$ microstrip line, and (d) the $9.5 \mathrm{GHz}$ band-pass filter.

In the measurement process, the characteristics of the microstrip lines and microwave filters were characterized through ground-signal-ground (GSG) probes (Cascade $250 \mu \mathrm{m}$ pitch) connected to an HP E8364C vector network analyzer (VNA, Agilent, Palo Alto, California, USA) on a probe station. More details about the engineering design processes are presented in our previous publications [14,15].

\section{Bending Limit Tests and Discussion}

In Section 2, the introduced bending vehicles are semi-cylinders, and the filters were fixed onto the surface of the semi-cylinder to achieve bending effects. However, when the radius of the semi-cylinder reduces to a certain degree, the filters cannot be fixed to the bending vehicles anymore. To testing the bending limit radius, a cylinder vehicle with radius of $1.5 \mathrm{~mm}, 1 \mathrm{~mm}$, and $0.75 \mathrm{~mm}$ was used. The radius of the cylinder is much smaller than the previous semi-cylinder vehicle, with the minimum radius of $5 \mathrm{~mm}$. The microstrip lines and filters were wrapped onto the surface of the cylinder using strong adhesive transparent tapes, then opened and glued on the probe station to testing the S-parameters. Figure 2 shows the bending test flow of the $50 \Omega$ microstrip lines.

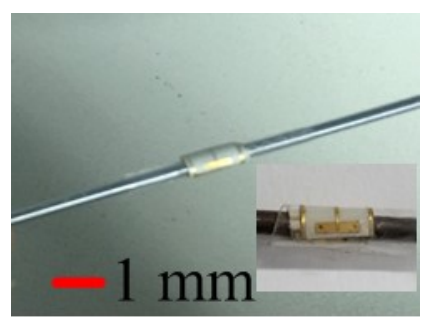

(a)

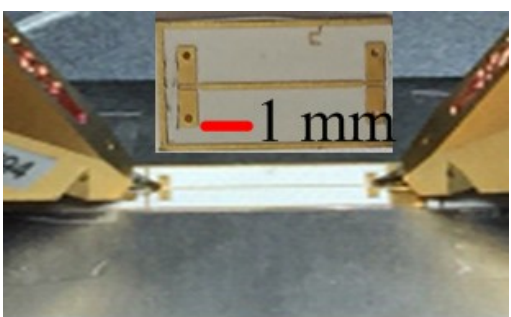

(b)

Figure 2. Flow of measurement setup of microstrip line. (a) Warp it onto the surface of the cylinder and (b) open and stick it on a plate metal on the probe station.

\subsection{Results of Bending Limit Tests of the Microwave Components}

Following the test flows, Figure 3 shows the bending limit test results versus frequency for the $50 \Omega$ microstrip lines, band-pass filters, and low-pass filters. In Figure 3 , it can be seen that the performance of the microstrip lines and filters has little deterioration under the bending radii from $1.5 \mathrm{~mm}$ to $1 \mathrm{~mm}$. However, when the radius was reduced to $0.75 \mathrm{~mm}$, the insertion loss of microstrip 
lines was sharply increased to $30 \mathrm{~dB}$, showing complete reflection phenomenon; the insertion loss and return loss of the band-pass filters deteriorated to $15 \mathrm{~dB}$ and $3 \mathrm{~dB}$ in the pass-band, respectively; the maximum insertion loss of the low-pass filters also deteriorated from $1.5 \mathrm{~dB}$ to $4.5 \mathrm{~dB}$ at $9 \mathrm{GHz}$. The deteriorated performance of all the components was so severe that they were no longer able to work normally.

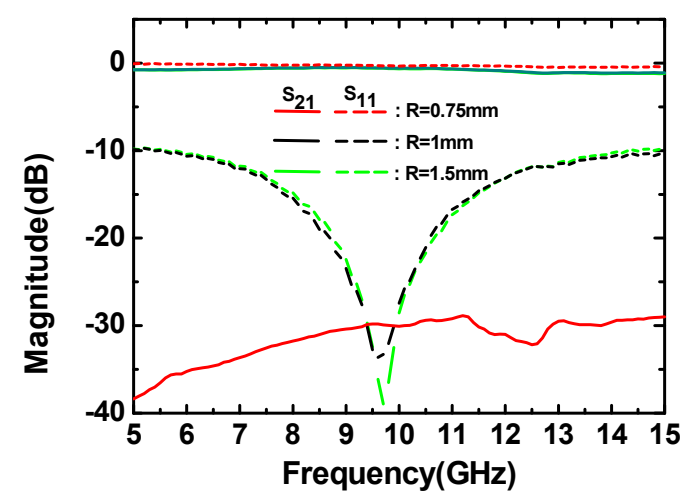

(a)

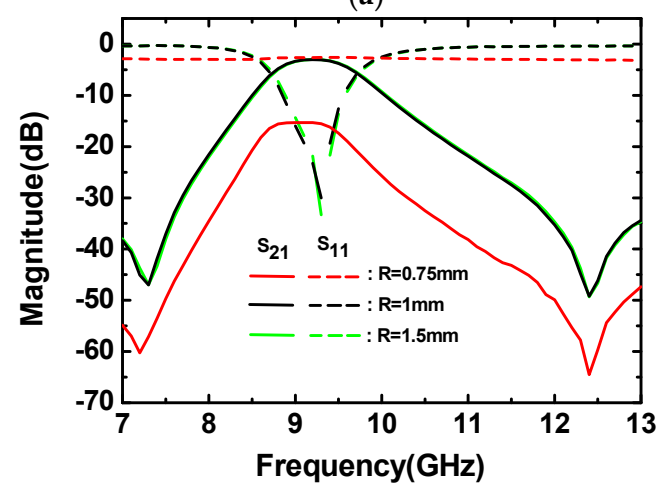

(b)

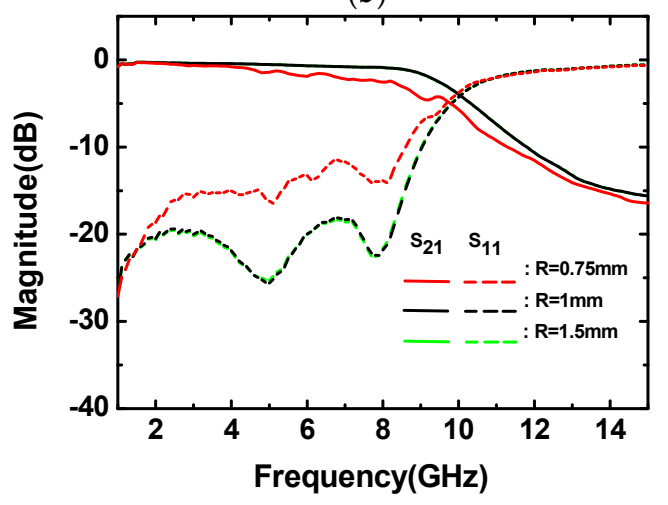

(c)

Figure 3. The limit test results (radii of $1.5 \mathrm{~mm}, 1 \mathrm{~mm}$, and $0.75 \mathrm{~mm}$ ). (a) Results of the $50 \Omega$ microstrip lines. (b) Results of the band-pass filters. (c) Results of the low-pass filters.

Hence, the range of radius, from $1 \mathrm{~mm}$ to $0.75 \mathrm{~mm}$, can be estimated as the limit bending radius for this LCP substrate, meaning that any kind of bending behavior with bending radius less than $1 \mathrm{~mm}$ might disable components, devices, and systems based on this LCP substrate.

\subsection{Study and Discussion of the Failure Mechanism}

In the bending limit tests for the microwave components, the frequency shift and increased insertion loss are observed, which is caused by a mechanical deformation of the metallization microstrip. When the microstrip line is under bending situation, the copper trace of the microstrip lines 
would be stretched, and the thickness and the roughness would become thinner and non-uniform, respectively. The stability of the metallization to LCP substrate adhesion would also be reduced, leading to a higher sheet resistance [17]. When the stretched force approached its critical point, the microstrip lines are broken, and the microwave components' performance collapses. To research the failure mechanism of these components, the breakage of metallization microstrips after bending tests are observed under the microscope. Figure 4 shows the images of cracked points along the microstrip line and transition junction between the microstrip line and ground coplanar waveguide (GCPW) feeding ports.

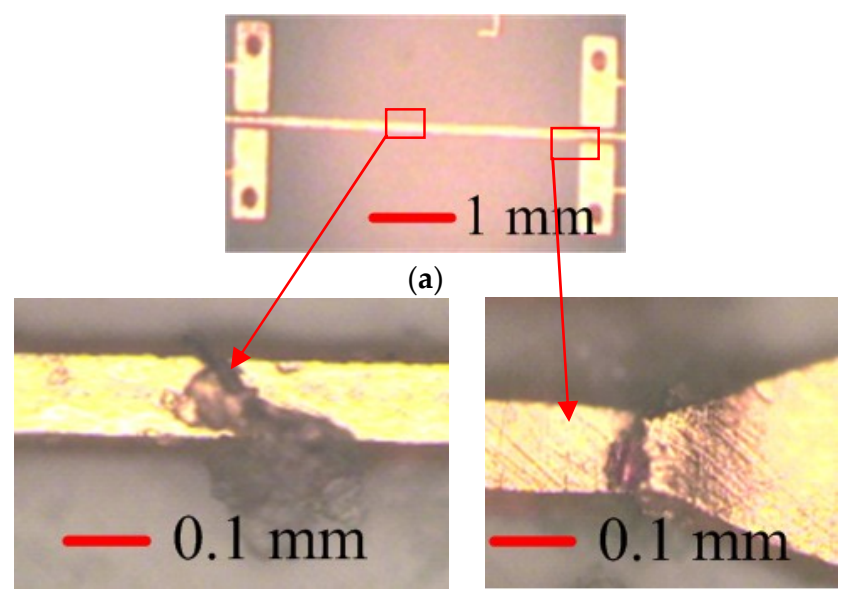

(b)

(c)

Figure 4. Microscope images of the cracked points. (a) Zoomed out image after the bending test, where the squares are the breaking points; (b) cracked point along the microstrip line; and (c) cracked point at the transition of microstrip line and ground coplanar waveguide (GCPW).

From Figure 4, it can be seen that the microstrip lines cracked along the signal trace, which is equal to introducing a capacitance (Cadd) along the signal trace [20], as shown in Figure 5. The gaps suddenly change the impedance of the reference plane at the cracked points, which is the reason for the insertion loss sharply increasing, and the complete reflection phenomenon of the microstrip lines and the band-pass filters.

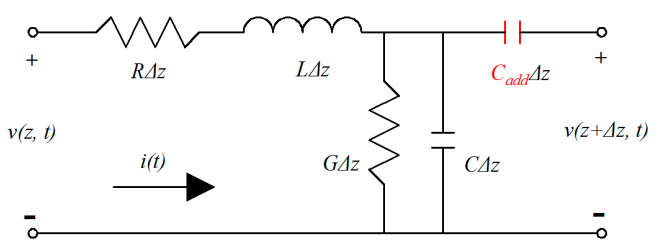

Figure 5. The lumped equivalent circuit of the collapsed transmission lines [21].

As we can see from the results in Figures 3 and 4, under high strain level, the straight microstrip line is fragile, and the coupling structure is much more sensitive than the direct connecting structures. In future flexible microwave circuits and systems, the mender microstrip lines can offer more robust performance under high strain levels, and the coupling structures may not be suitable for high strain level applications.

For the interface failure between the flexible substrates and films, three types of failure modes, which are fracture, slipping, and delamination, are presented [21], depending on different materials and various combinations of the thickness of flexible substrates and films. It can be expected that the thickness of films would play a very important role for the types of failure modes under bending situations. Cracking mode would occur when the films are very thin relative to the flexible substrate's 
thickness; then, as the films' thickness increases, the slipping mode appears; if increasing the films further, whole films would be exfoliated from the substrate, forming the delamination mode.

In this case, the copper thickness is $18 \mu \mathrm{m}$, and the substrate thickness is $50 \mu \mathrm{m}$ for the LCP substrate 3850 (Rogers Corporation, city, state, USA). It is possible that the slipping or delamination failure modes should be observed according to the theory in [21], but the only failure mode of fracture was observed. The reason for that is that the strength of the adhesive bonding between films and substrates is another sensitive parameter for the types of failure modes. The LCP 3850 is a commercialized version from Rogers Corporation, so the strength of the adhesive bonding is excellent, avoiding the slipping and delamination between the film and the substrate.

It can be seen from the Figure 3 that the performance of the microwave components has little deterioration, even under the bending radii of $1 \mathrm{~mm}$. However, when the radius decreased to $0.75 \mathrm{~mm}$, the devices collapsed suddenly without appreciable signs of transition. The reason is that the flexible components have bare deterioration, even under the bending radius of $1 \mathrm{~mm}$; however, the components sharply collapsed when the bending radius was reduced to $0.75 \mathrm{~mm}$.

\section{Conclusions}

In this paper, bending limit tests were carried out for LCP substrate, and the results show that the bending limit radius range is about from $1 \mathrm{~mm}$ to $0.75 \mathrm{~mm}$ for this LCP. Then, the failure mechanism and reasons for the collapsing of these microwave circuits are also studied. This paper revealed the bending limit parameters for LCP substrate in microwave range, which would be a significant assessment for future high-frequency flexible devices and systems based on an LCP substrate.

Author Contributions: Investigation, methodology, writing, original draft-Y.L.; Supervision, review \& editing-Y.X.

Funding: This research was funded by National Natural Science Foundation of China under Grant No. 61106115, 61474020 and 61201004.

Conflicts of Interest: The authors declare that there is no conflict of interests regarding the publication of this article.

\section{References}

1. Thompson, D.; Tantot, O.; Jallageas, H.; Ponchak, G.; Tentzeris, M.; Papapolmerou, J. Characterization of Liquid Crystal Polyer (LCP) Material and Transmission Lines on LCP Substrate From 30-110 GHz. IEEE Trans. Microw. Theory Tech. 2004, 52, 1343-1352. [CrossRef]

2. Khan, W.T.; Morcillo, D.; Ulusoy, C.A.; Papapolymerou, J. Characterization of liquid crystal polymer from 110GHz to 170GHz. In Proceedings of the Radio and Wireless Symposium, Newport Beach, CA, USA, 19-23 January 2014.

3. Zhang, X.; Kuylenstierna, D.; Liu, J.; Cae, P.; Andersson, C.; Morris, J.; Zirath, H. A compact V-band planar wideband bandpass filter based on Liquid Crystal Polymer substrates. In Proceedings of the 2nd Electronics System integration Technology Conference, Greenwich, UK, 1-4 September 2008.

4. Ye, J.D.; Qu, D.X.; Zhong, X.J.; Zhou, Y.X. Design of X-band Band-pass Filter Using Hairpin Resonators and Tapped Feeding Line. In Proceedings of the Symposium on Computer Applications and Communications, Weihai, China, 26-27 July 2014.

5. Cervera, F.J.; Hong, J.S. Compact Self-Packaged Dual-band Filter Using Multilayer Liquid Crystal Polymer Technology. IEEE Trans. Microw. Theory Tech. 2014, 62, 2618-2625. [CrossRef]

6. Chlieh, O.L.; Khan, W.T.; Papapolymerou, J. L-band Tunable Microstrip Band-pass Filter on Multilayer Organic Substrate with Integrated Microfluidic Channel. In Proceedings of the IEEE MTT-S International Microwave Symposium, Tampa, FL, USA, 1-6 June 2014.

7. Zhang, Y.F.; Shi, S.Y.; Martin, R.; Yao, P.; Shreve, K.; Prather, D.W. Multilayer Liquid Crystal Polymer Based RF Front-end Module for Millimeter Wave Imaging. In Proceedings of the IEEE Antennas and Propagation Society International Symposium, Memphis, TN, USA, 6-11 July 2014. 
8. Mamidanna, M.; Pham, A.V.; Montauti, F. Development of a Liquid Crystal Polymer Low Noise Amplifier Module at Ka-band. In Proceedings of the IEEE MTT-S Int. Microwave Sym, Tampa, FL, USA, 1-6 June 2014.

9. Qiu, Y.J.; Jung, Y.H.; Lee, S.; Shih, T.Y.; Lee, J.H.; Xu, Y.H.; Lin, W.G.; Behdad, N.; Ma, Z.Q. Compact parylene-c-coated flexible antenna for WLAN and upper-band UWB applications. Electron. Lett. 2014, 50, 1782-1784. [CrossRef]

10. Geise, A.; Strohmaier, U.; Jacob, A.F. Investigations of Transmission Lines and Resonant Structures on Flexed Liquid Crystal Polymer (LCP) Substrates up to 67 GHz. In Proceedings of the Microwave Conference, Rome, Italy, 29 September-1 October 2009.

11. Kao, H.L.; Cho, C.L.; Dai, X.; Yeh, C.S.; Zhang, X.Y.; Chang, L.C.; Chiu, H.C. Hairpin Band-pass Filter on Liquid Crystal Polymer Substrate using Inkjet Printing Technology. In Proceedings of the IEEE MTT-S International Microwave Symposium Digest, Seattle, WA, USA, 2-7 June 2013.

12. Kao, H.L.; Cho, C.L.; Chang, L.C. Inkjet-Printed Interdigital Coupled Line Filter on Liquid Crystal Polymer Substrate. IEEE Electron. Device Lett. 2013, 34, 1584-1586. [CrossRef]

13. Kao, H.L.; Yeh, C.S.; Zhang, X.Y.; Cho, C.L.; Dai, X.; Wei, B.H.; Chang, L.C.; Chiu, H.C. Inkjet Printed Series-Fed Two-Dipole Antenna Comprising a Balun Filter on Liquid Crystal Polymer Substrate. IEEE Trans. Compon. Packag. Manuf. Technol. 2014, 4, 1228-1236.

14. Lan, Y.; Xu, Y.H.; Wang, C.S.; Wen, Z.; Qiu, Y.J.; Mei, T.D.; Wu, Y.Q.; Xu, R.M. X-band Flexible Band-pass Filter Based on Ultra-thin Liquid Crystal Polymer Substrate. Electron. Lett. 2015, 51, 345-347. [CrossRef]

15. Lan, Y.; Xu, Y.H.; Wang, C.S.; Wen, Z.; Qiu, Y.J.; Mei, T.D.; Wu, Y.Q.; Xu, R.M. Flexible Microwave Filters on Ultra Thin Liquid Crystal Polymer substrate. In Proceedings of the IEEE MTT-S International Microwave Symposium, Phoenix, AZ, USA, 17-22 May 2015.

16. Dagdeviren, C.; Su, Y.W.; Joe, P.; Yona, R.; Liu, Y.H.; Kim, Y.S.; Huang, Y.A.; Damadoran, A.R.; Xia, J.; Martin, L.W.; et al. Conformable Amplified Lead Zirconate Titanate Sensors with Ehanced Piezoelectric Response for Cutaneous Pressure Monitoring. Nat. Commun. 2014, 5, 4496-4506. [CrossRef] [PubMed]

17. Akinwande, D.; Petrone, N.; Hone, J. Two-dimensional flexible nanoelectronics. Nat. Commun. 2014, 5, 5678-5689. [CrossRef] [PubMed]

18. Advanced Circuit Materials Division, Rogers Corporation. ULTRALAM®3000 Liquid Crystalline Polymer Circuit Material. Rogers, CT. 2014. Available online: http://www.rogerscorp.cn (accessed on 18 October 2018).

19. Tsai, C.M.; Lee, S.Y.; Tsai, C.C. Performance of a Planar Filter Using a 0 Feed Structure. IEEE Trans. Microw. Theory Tech. 2002, 50, 2362-2367. [CrossRef]

20. Pozar, D.M. Microwave Engineering, 3rd ed.; Publishing House of Electronics Industry: Beijing, China, 2005; Volume 2, pp. 42-43.

21. Park, S.; Ahn, J.H.; Feng, X.; Wang, S.D.; Huang, Y.G.; Rogers, J.A. Theoretical and Experimental Studies of Bending of Inorganic Electronic Materials on Plastic Substrates. Adv. Funct. Mater. 2008, 18, 2673-2684. [CrossRef]

(C) 2018 by the authors. Licensee MDPI, Basel, Switzerland. This article is an open access article distributed under the terms and conditions of the Creative Commons Attribution (CC BY) license (http://creativecommons.org/licenses/by/4.0/). 